\title{
South African medical schools: Current state of selection criteria and medical students' demographic profile
}

\author{
L J van der Merwe, ${ }^{1} \mathrm{MB}$ ChB, MMedSc, PhD; G J van Zyl, ${ }^{1}$ MB ChB, MFamMed, MBA, Dipl Community Health, Dipl Health \\ PhD; G C Botha, ${ }^{5} \mathrm{MA}$; D Manning, ${ }^{6} \mathrm{BSc}$ Hons, MEd, PhD; S J Botha, ${ }^{7}$ BSc Hons, MSc, PhD; R Hift, ${ }^{7} \mathrm{MB} \mathrm{ChB}, \mathrm{MMed}, \mathrm{PhD}$; \\ ${ }^{1}$ Faculty of Health Sciences, University of the Free State, Bloemfontein, South Africa \\ ${ }^{2}$ Faculty of Health Sciences, Walter Sisulu University, Mthatha, Eastern Cape, South Africa \\ ${ }^{3}$ Faculty of Health Sciences, University of Cape Town, Cape Town, South Africa \\ ${ }^{4}$ Faculty of Health Sciences, University of the Witwatersrand, Johannesburg, South Africa \\ ${ }^{5}$ Sefako Makgatho Health Sciences University, Ga-Rankuwa, Gauteng, South Africa \\ ${ }^{6}$ Faculty of Health Sciences, University of Pretoria, Pretoria, South Africa \\ ${ }^{7}$ College of Health Sciences, University of KwaZulu-Natal, Howard College, Durban, South Africa \\ ${ }^{8}$ Faculty of Medicine and Health Sciences, Stellenbosch University, Tygerberg, Cape Town, South Africa
} Administration, PhD; A St Clair Gibson, ${ }^{1} \mathrm{MB} \mathrm{ChB}, \mathrm{PhD}, \mathrm{MD} ; \mathbf{M}$ Viljoen, ${ }^{1}$ BComm, MBA; J E Iputo, ${ }^{2} \mathrm{MB}$ ChB, PhD; M Mammen, ${ }^{2} \mathrm{MSc}$, PhD, FAIMER; W Chitha, ${ }^{2} \mathrm{MB}$ ChB, MPH Health Economics, AMDP; A M Perez, ${ }^{3}$ DBS, DHSM, MDent; N Hartman, ${ }^{3}$ BA, BSocSc Hons, MSocSc, PhD; S Fonn, ${ }^{4} \mathrm{MB}$ BCh, FFCH, PhD; L Green-Thompson, ${ }^{4}$ MB BCh, FCA (SA); O A Ayo-Ysuf, ${ }^{5}$ BDS, MSc (Odont), DHSM, MPH, P Retief, ${ }^{8}$ BA Hons, MA, DLitt; B B van Heerden, ${ }^{8}$ MB ChB, MSc, MMed; J Volmink, ${ }^{8}$ MB ChB, DCH, FRCP (Edin), MPH, DPhil

Corresponding author: L van der Merwe (merwelj@ufs.ac.za)

\begin{abstract}
Background. Selection of medical students at South African (SA) medical schools must promote equitable and fair access to students from all population groups, while ensuring optimal student throughput and success, and training future healthcare practitioners who will fulfil the needs of the local society. In keeping with international practices, a variety of academic and non-academic measures are used to select applicants for medical training programmes in SA medical schools.

Objectives. To provide an overview of the selection procedures used by all eight medical schools in SA, and the student demographics (race and gender) at these medical schools, and to determine to what extent collective practices are achieving the goals of student diversity and inclusivity.

Methods. A retrospective, quantitative, descriptive study design was used. All eight medical schools in SA provided information regarding selection criteria, selection procedures, and student demographics (race and gender). Descriptive analysis of data was done by calculating frequencies and percentages of the variables measured.

Results. Medical schools in SA make use of academic and non-academic criteria in their selection processes. The latter include indices of socioeconomic disadvantage. Most undergraduate medical students in SA are black (38.7\%), followed by white (33.0\%), coloured (13.4\%) and Indian/Asian (13.6\%). The majority of students are female (62.2\%). The number of black students is still proportionately lower than in the general population, while other groups are overrepresented.

Conclusion. Selection policies for undergraduate medical programmes aimed at redress should be continued and further refined, along with the provision of support to ensure student success.
\end{abstract}

S Afr Med J 2016;106(1):76-81. DOI:10.7196/SAMJ.2016.v106i1.9913

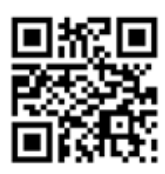

Selection procedures in most medical schools are necessary because substantially more applications are received than the number of places available. Medical schools have a duty to ensure that students admitted to their programmes have the potential to successfully complete their studies and display competent and ethical behaviour in practice. ${ }^{[1]}$ In South Africa (SA), there is also an imperative to ensure that adequate numbers of quality candidates are attracted and selected, not only to ensure their academic success, but also to provide future healthcare practitioners who are fit to practise in the local society, including rural and currently under-served areas in the country. Selection instruments must therefore be aligned with social accountability objectives, so that widening access is granted to those from a disadvantaged background and to ensure access across the entire demographic profile of SA. At a meeting of representatives of the South African Committee of Medical Deans, a decision was made to employ collective learning from current practices across medical schools in SA to point the way forward.
A variety of indicators, tests, procedures and methods are used to select candidates for places in medical school, which include both academic proficiency and non-academic characteristics. Although it has been argued that certain core competencies important for future doctors should be considered in the selection process, this does not necessarily predict academic success, ${ }^{[2]}$ nor does it assure that socially accountable practitioners are produced. At the same time, there is uncertainty as to whether the widely accepted view that academic success at high school is the best predictor of academic success at medical studies holds true. ${ }^{[3]}$

Selection procedures at SA medical schools currently employ pooled data from academic performance tests indicating cognitive ability, comprising a combination of the National Senior Certificate (NSC) results in compulsory subjects and the National Benchmark Tests (NBT), and non-academic performance indicators. The latter include performance in extracurricular activities (leadership, sport, cultural, community engagement and service), measures of disadvantage such as family income, schooling and rural origin, personal reports (biographical 
questionnaires) and interviews. Each medical school employs a particular combination of these admission criteria, but currently there is no uniformity in how they are applied across the medical schools.

A positive correlation between past academic achievement and future academic success has been demonstrated by previous research ${ }^{[4]}$ However, in a group of applicants with exceptional academic achievement in certain compulsory subjects at NSC level, it is not possible to predict among top achievers who is more or less likely to succeed. The NBT provides an additional method of differentiating cognitive ability by testing language, mathematical and reasoning ability. Internationally, tests such as the General Cognitive Ability test have been shown to have a significant relationship with future academic and career success. ${ }^{[1]}$ In SA, data are lacking regarding the relationship between the NBT and success at medical school.

Non-academic tests are often used as additional measures to differentiate between applicants with exemplary cognitive ability, to ensure that candidates with desirable traits for future medical practice are not excluded by focusing solely on academic performance. However, the reliability and validity of non-academic performance as selection criteria are debatable. ${ }^{[5]}$ Scientific evidence of the predictive value of various selection criteria and processes is needed to guide future practice.

In $\mathrm{SA}$, in an attempt to address historical inequalities with regard to access, medical schools attempt to select candidates reflecting the demographic profile of the country, and therefore aim to increase the number of black African and coloured students selected for medical training ${ }^{[6]}$ However, the demographic data regarding racial composition of student cohorts at individual medical schools may still not reflect that of the country at large. There are different demographic distributions in the geographical areas and provinces of SA, and the number of applicants who comply with minimum selection criteria in each of these areas may be insufficient to meet the required targets for transformation. All medical schools, however, are committed to transformation in their selection practices. The number of applicants who decline an offer of a place at a particular medical school because they have been accepted at another institution, poses difficulties for medical schools to increase the number of students in specific target groups. In addition to optimal selection processes, the throughput of selected candidates from first year to graduation needs to be monitored in order to reduce challenges experienced by students to complete their studies in the minimum time.

With 2014 marking the 20-year anniversary of democracy in SA, selection procedures continue moving towards methods of providing improved access to students from disadvantaged backgrounds. However, defining disadvantage by race has become complicated by the fact that there is an emerging black middle class. Factors such as schooling and educational background (for example, quintile 1 and 2 schools $\left.{ }^{[7]}\right)$, rurality and socioeconomic circumstances have therefore been included as indicators of disadvantage. Further complexities exist, such as the emerging middle class and the fact that children of domestic workers, for example, often attend good schools in the area where their parents are employed. Students' financial need, ${ }^{[8]}$ the variable quality of primary and secondary schooling ${ }^{[9]}$ and the importance of taking into account cultural differences in the selection process, are additional issues pointing to the need for a comprehensive re-evaluation of selection criteria.

\section{Objectives}

To provide information regarding the current selection criteria and medical student demographics at the eight SA medical schools, and to determine to what extent collective practices are achieving the goals of student diversity and inclusivity.

\section{Methods}

A retrospective, quantitative, descriptive study design was followed. All eight medical schools in SA, as listed in Table 1, participated in the study in 2014. Representatives from the South African Committee of Medical Deans at each institution provided information regarding selection criteria, selection procedures, and student demographics regarding race and gender.

Information on selection policies, criteria and procedures for 2014 included both academic and non-academic performance indicators used to select candidates for medical studies at SA medical schools. Demographic variables included gender and race (black, coloured, Indian/Asian, white and 'other', where 'other' mainly referred to students from Southern African Development Community (SADC) countries) of students who were offered places at the respective medical schools, students who accepted these places, and the registered students' demographic characteristics in 2014. Descriptive analysis of data was done by calculating frequencies and percentages of the variables measured.

\section{Results}

As shown in Table 1, all eight medical schools in SA participated in the study. All the medical schools offer a 6-year curriculum for the undergraduate medical degree, with the exception of the UFS, where a 5-year curriculum is followed. Extended programmes are available at UCT, UFS, SMU, SUN and UP, and a graduate entry programme at WITS. UCT has not yet introduced a graduate entry programme, although one or two students with degrees are offered places in second year. All the universities offer structured student support programmes.

In 2014, a total of approximately 1900 places were available at these institutions for first-year medical students (UCT 220, UFS 140, UKZN 250, SMU 250, UP 300, SUN 290, WITS 250, WSU 120). These places included positions offered to students who have completed the NSC (matriculants/school leavers), as well as senior students, foreign students, dean's/rector's places, and students transferring from other medical schools, health sciences professions or degree programmes. Each university, however, has its own rules regarding the admission of medical students.

Table 2 provides an overview of the NSC and NBT academic requirements and the weighting applied at each of the institutions for admission to their undergraduate medical programmes in 2014.

The demographic composition of selected applicants with regard to race and gender varies at different medical schools. All medical schools aim to include students from all races and both genders in their admissions, and make use of different criteria to achieve

Table 1. SA medical schools and abbreviations (in alphabetical order)

\begin{tabular}{ll}
\hline University & Abbreviation \\
\hline Sefako Makgatho Health Sciences University & SMU \\
Stellenbosch University & SUN \\
University of Cape Town & UCT \\
University of the Free State & UFS \\
University of KwaZulu-Natal & UKZN \\
University of Pretoria & UP \\
University of the Witwatersrand & WITS \\
Walter Sisulu University & WSU \\
${ }^{*}$ Formerly University of Limpopo Medunsa Campus. &
\end{tabular}


inclusivity in terms of black and coloured students, as well as those from disadvantaged backgrounds. At UCT, the Senate approves targets by population group for school leavers annually. No targets are set for gender, and students from rural areas may enter through special consideration with slightly lower cut-off points. At the UFS, which follows a parallel-medium language policy, the selection committee aims to select English and Afrikaans students in a ratio of $60: 40$, while the female/male ratio is $60: 40$ in order to ensure that minorities are represented. The ratio with regard to gender is maintained so that, for example, female students cannot be more than $60 \%$ of the selected applicants. A definite attempt is made to include candidates from disadvantaged backgrounds who demonstrate academic potential, while two points are allocated for rural origin.

At UKZN, 28\% of students are selected from quintile 1 and 2 schools ${ }^{[7]}$ without racial quotas, while $52 \%$ are selected on merit, with $69 \%$ of these places reserved for black students, $19 \%$ for Indian, $9 \%$ for coloured, $2 \%$ for white and $1 \%$ for other (Chinese) students. The remaining $20 \%$ of the total number of students admitted are selected from students with prior tertiary education. At SMU, $20 \%$ of the 250 spaces available for first-year medical students are reserved for students from the foundation programme (i.e. the extended curriculum programme). The remaining students are selected from matriculants and senior students transferring from other programmes. Of these, $78 \%$ of places are offered to black students, $11 \%$ to white, $8 \%$ to coloured and $3 \%$ to Indian students. No allowance is made for gender or disadvantage.

At UP, targets are set for historically disadvantaged students, namely black and coloured, while at SUN male and female students are selected in the same ratio as the pool of qualifying applicants, and selection based on race is in accordance with enrolment planning of the university and its commitment to inclusivity and diversity. At WITS, selection is made in two racially defined groups, namely coloured/black and white/Indian, to achieve a representative demographic distribution.

Academic requirements include NSC results and compulsory subjects at specified levels of achievement (level $5(>60 \%)$ ). These subjects include Mathematics, Physical Science, Life Science and Language (English). NBTs are required by UCT (70:30), UFS (60:40), UP (60:40), SUN (45:30) and WITS (50:50), with varying weight attributed to these results (NSC:NBT ratios indicated in parentheses). UKZN, SMU and WSU do not require students to write NBTs in their selection process.

Table 2. Academic (NSC and NBT) requirements for selection for undergraduate medical training at eight SA medical schools

\begin{tabular}{|c|c|c|c|c|c|}
\hline University & Academic (weight) & $\begin{array}{l}\text { APS (minimum required } \\
\text { based on NSC) }\end{array}$ & $\begin{array}{l}\text { NCS compulsory subjects }+ \text { minimum } \\
\text { achievement level }\end{array}$ & NBT requirements & NSC:NBT \\
\hline SMU & $100 \%$ & 30 & $\begin{array}{l}\text { Level } 5 \text { (60 - 69\%) } \\
\text { Maths, Physical Science, Life Science }\end{array}$ & Not required & NA \\
\hline SUN & $\begin{array}{l}45 \% \text { of selection } \\
\text { factor (grade } 11 / \\
\text { matric average) }\end{array}$ & Not applicable & $\begin{array}{l}\text { Level } 6(70-79 \%) \text { or higher } \\
\text { Level } 4(50-59 \%) \text { or higher } \\
\text { Maths, Physical Science, Life Science }\end{array}$ & $\begin{array}{l}\text { Intermediate or } \\
\text { proficient } \\
\text { Minimum } 38 \% \text { per } \\
\text { component } \\
\text { Weight: } 30 \% \text { of } \\
\text { selection factor }\end{array}$ & $45: 30$ \\
\hline UCT & $\begin{array}{l}\text { NSC score out } \\
\text { of } 600 \text { and NBT } \\
\text { score out of } 300+ \\
\text { (for Medicine) an } \\
\text { optional personal } \\
\text { report out of } 100\end{array}$ & $450($ APS $=$ NSC) & $\begin{array}{l}\text { Level } 5 \text { ( } 60 \text { - 69\%) } \\
\text { Compulsory: English, Maths, Physical } \\
\text { Science, plus next } 3 \text { best subjects } \\
\text { excluding LO }\end{array}$ & $\begin{array}{l}\text { Intermediate or } \\
\text { proficient. }\end{array}$ & $70: 30$ \\
\hline UFS & 100 points $(84.76 \%)$ & 36 & $\begin{array}{l}\text { Level } 5(60-69 \%) \\
\text { Language, Maths, Physical Science, } \\
\text { Life Science }\end{array}$ & $\begin{array}{l}\text { Must pass each } \\
\text { component and } \\
\text { average } 50 \% \text { overall }\end{array}$ & $60: 40$ \\
\hline UKZN & $\begin{array}{l}\text { Aggregate of } 4 \\
\text { compulsory subjects } \\
+2 \text { best subjects, } \\
\text { excluding Maths } 3 \\
\text { and LO }\end{array}$ & Not applicable & $\begin{array}{l}\text { Level } 5 \text { ( } 60-69 \%) \\
\text { English, Maths, Physical Science, } \\
\text { Life Science } \\
\text { Average } 65 \%\end{array}$ & Not required & NA \\
\hline UP & $100 \%$ & 35 (excluding LO) & $\begin{array}{l}\text { Level } 5(60-69 \%) \\
\text { Language, Maths, Physical Science or } \\
\text { Life Science }\end{array}$ & $\begin{array}{l}\text { AL } 20 \% \text {, QL 20\%, } \\
\text { Maths } 60 \%\end{array}$ & $60: 40$ \\
\hline WITS & $\begin{array}{l}\text { Composite index: } \\
\text { NSC } 40 \% \text {, NBT } 40 \% \text {, } \\
\text { BQ } 20 \%\end{array}$ & Not applicable & $\begin{array}{l}\text { Level } 5 \text { ( } 60-69 \%) \\
\text { English, Maths, Physical Science or } \\
\text { Life Science, plus next } 2 \text { best subjects } \\
\text { incl. LO }\end{array}$ & Required & $50: 50$ \\
\hline WSU & $\begin{array}{l}\text { Academic 50\%; } \\
\text { interview 50\% }\end{array}$ & 20 (4 subjects) & $\begin{array}{l}\text { Level } 5 \text { ( } 60-69 \%) \\
\text { English, Maths, Physical Science, } \\
\text { Life Science }\end{array}$ & Not required & NA \\
\hline
\end{tabular}


The non-academic requirements for selection for medical training carry between $10 \%$ and $25 \%$ of the total weight during the selection process, and comprise the following:

Extracurricular activities. These include leadership, community service, cultural and sporting achievements, of which UCT, UFS, UP, SUN and WITS include different components in the selection process.

Region of origin. Although UCT does not allocate extra points for region of origin, rural students may be admitted with lower cut-off points than the general pool of applicants. UFS offers an additional 2 points and SUN an additional 4 points for applicants of rural origin, while WSU tends to admit more of its students from rural Eastern Cape areas.

Advantage based on parents being alumni or staff members of the institution is given in the form of 2 additional points at UFS and SUN.

Indices of disadvantage are specified at UCT to include redress for groups 1 and 2 (black and coloured students) who enter with lower points, redress for group 3 (Indian students) who enter with the same cut-off point as 'Open' students (who must meet requirements without dropping cut-off points), and redress for group 4 (Chinese) who may enter with points slightly lower than the Open group. At UP disadvantage is seen as historically based on race, while at SUN no disadvantage index is used as it is implicit in the selection process. At UKZN and SUN (for selection of students to the extended programme), schooling background (e.g. quintile 1 and 2 schools $^{[7]}$ ) is taken into consideration. At SMU applicants from quintile 1 and 2 schools are considered for the extended curriculum programme if they have not been selected directly into the medical programme on competitive basis.

Biographical questionnaires, personal reports or interviews. At UCT a personal report will be required from 2016 if students achieve at a high level with their NSC and NBT results. WITS has made use of a biographical questionnaire prior to admission for 2015. UFS conducted interviews in the past, while WSU currently uses interviews for selected students based on academic merit. The interview aims to assess students' personal attributes.

Fig. 1 shows the student demographic profile with regard to race and gender of all undergraduate students in the medical training programmes offered at SA medical schools during 2014. Among 9293 students, male students constitute $37.8 \%$ of the total group, with $62.2 \%$ female students. The

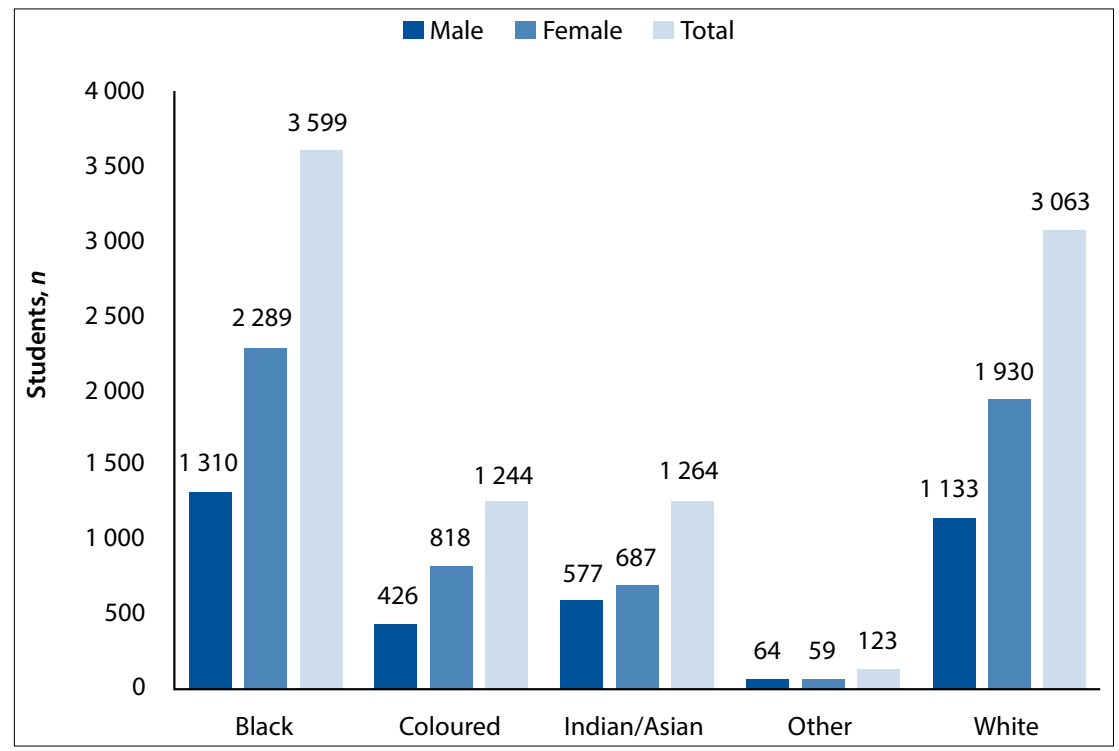

Fig. 1. Race and gender of undergraduate students at SA medical schools in 2014.

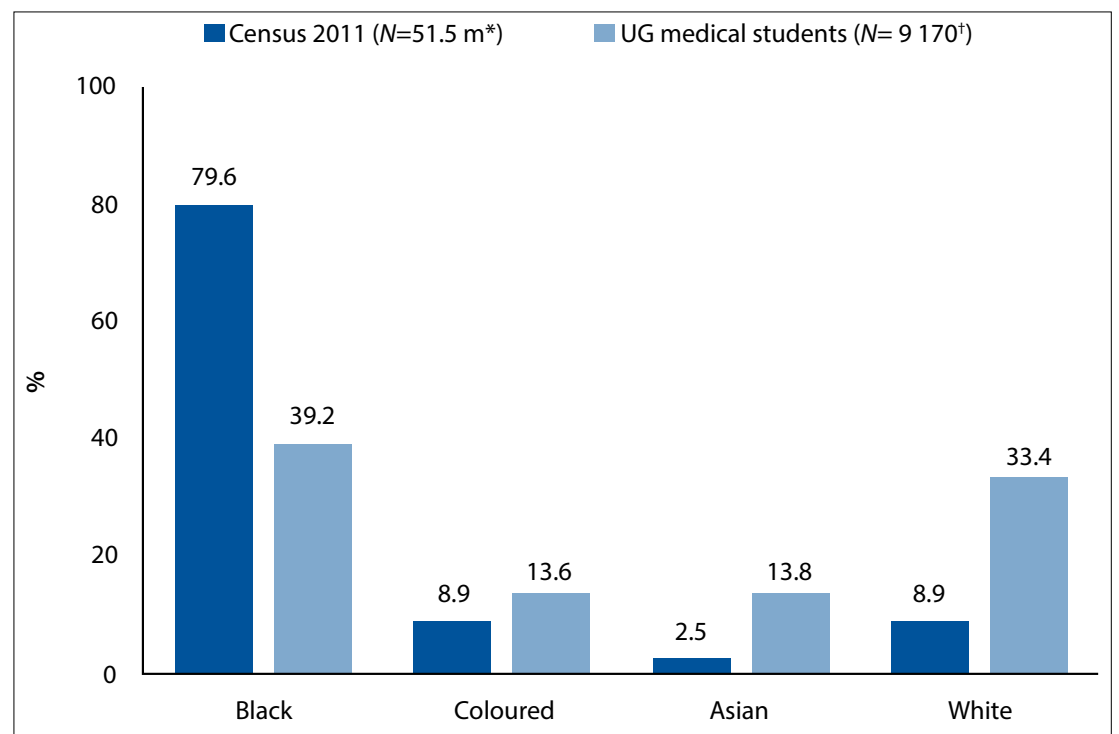

Fig. 2. Comparison of the racial distribution of the general $S A$ population and undergraduate medical students attending $S A$ medical schools in 2014. (UG $=$ undergraduate; ${ }^{*} 51.5$ million; ${ }^{\dagger} U G$ students enrolled at eight South African medical schools in 2014.)

majority of students are black $(38.7 \%)$, followed by white (33.0\%), coloured (13.4\%), Indian/Asian (13.6\%) and other (1.3\%).

Fig. 2 compares the racial distribution of undergraduate medical students in SA in 2014 with demographic findings of the National Census of 2011. ${ }^{[10]}$

Although the majority of medical students at SA universities are black (approximately $39 \%$ ), this group is still under-represented in relation to the national population, of which $80 \%$ of individuals are black. ${ }^{[10]}$ Medical students from the other racial groups are over-represented in comparison with the national demographic profile. Slightly more than $33 \%$ of medical students in 2014 were white, while whites represent less than $10 \%$ of the total population. In 2014, nearly $15 \%$ of medical students were coloured, while the coloured population comprises less than $10 \%$ of the total population in the 2011 census. More than 10\% of medical students were Indian/Asian, while Indians/ Asians represent less than $5 \%$ of the total population. ${ }^{[10]}$

At all eight medical schools, large differences are prevalent in the number of offers made compared with offers accepted. Students may receive more than one admission offer as they may have applied to more than one university. Therefore, the large cumulative number of offers made by the eight medical schools may be due to duplication. Large numbers of students 


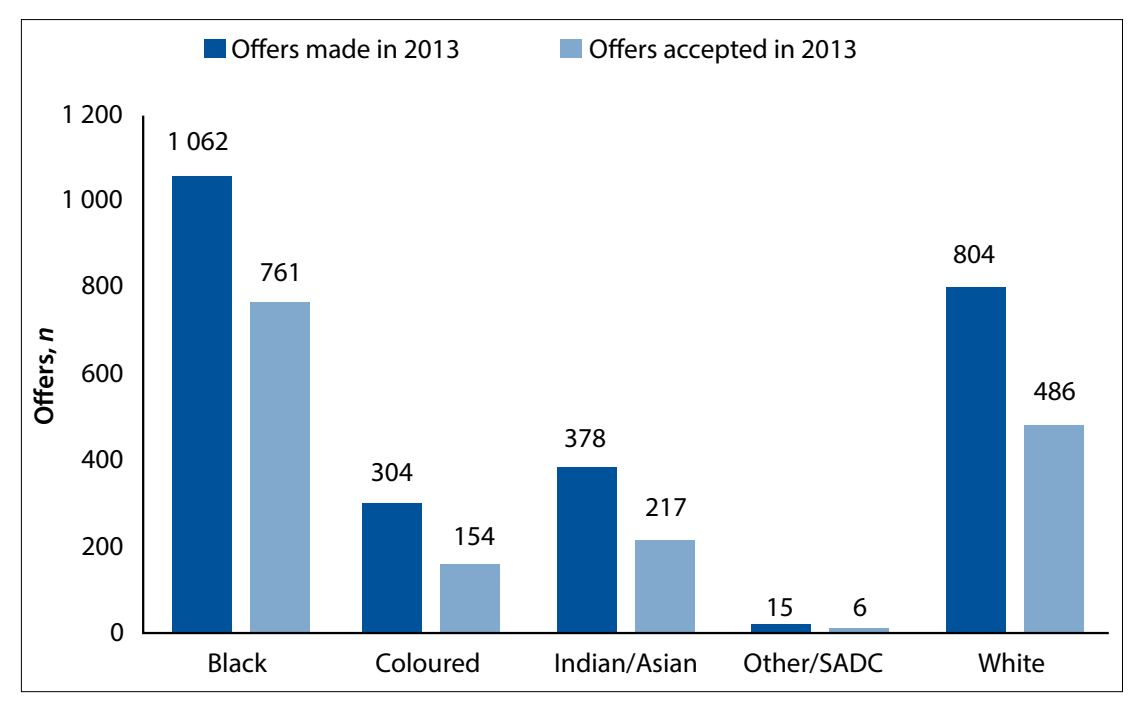

Fig. 3. Number of offers made and offers accepted in 2013 for admission for medical training in 2014 at all eight South African medical schools.

who are selected and do not take up the positions offered may therefore skew the representation of the different population groups eventually admitted at these institutions.

For 2014 admissions, only $67 \%$ of students accepted the offers made by medical schools. Black students made up $49.4 \%$ of the total offers made to students, and $46.9 \%$ of those who accepted these offers. Only $62.4 \%$ of black students accepted the offers made. White students comprised $27.3 \%$ of the offers made and $27.9 \%$ of the offers accepted. In this group, $61.8 \%$ accepted the offers made. Coloured students comprised $11.6 \%$ of the offers made, and made up $9.5 \%$ of those who accepted offers at medical school. In this group, $49.3 \%$ accepted the offers made. Of the offers made, $11.4 \%$ were to Indian/ Asian students, and of the offers accepted, $11.5 \%$ had been made to Asians. In this group, $61.2 \%$ accepted the offers made. Very low numbers of students in the group 'other' (including students from SADC countries) were offered places, and of these students only $40.0 \%(6 / 15)$ accepted the offers. There are no available data showing reasons for the difference between offers made and eventual admissions.

Fig. 3 represents the total number of offers made and accepted in 2013 for admission in 2014 at all eight medical schools.

At all institutions, with the exception of WSU, the number of students who take up positions offered to them was lower than the number of offers made. The largest number of offers made was to black and coloured students (53.3\%), redressing previous disadvantage, followed by white $(31.3 \%)$ and Indian/Asian (14.8\%) students. When looking at the number of students who accepted these offers, the majority (56.3\%) were black and coloured students, followed by white (29.9\%) and Asian/Indian students $(13.4 \%)$.

\section{Discussion}

All eight medical schools in SA use academic and non-academic requirements in their selection processes, conforming to international practice. ${ }^{[1,5]}$ In addition, these institutions aim to improve inclusivity among the students selected in order to meet the needs of the diverse socioeconomic and cultural populations that qualifying doctors will serve in future. For example, based on existing evidence, ${ }^{[11]}$ targeting students from rural areas may enhance the number of rural practitioners. This approach is in line with the World Health Organization (WHO) guidelines stating that admission policies should be targeted to reflect student diversity in terms of socioeconomic, ethnic and geographic background. ${ }^{[12]}$

We found that overall the demographic profile of selected students is beginning to reflect the diversity of the population groups in SA. Although the proportion of students in each population group varies between medical schools (probably reflecting the demographics of the province and region where the institution is situated), the percentage of students from historically disadvantaged racial groups (black and coloured students) has improved to a large although less so since 1999.[6] The largest number of students enrolled for training as doctors at SA medical schools are the black and coloured groups (52.1\%), followed by degree when compared with pre-1994, ${ }^{[13]}$ white $(33.0 \%)$ and Indian/Asian students (13.6\%). Black students remain underrepresented in medical schools compared with the national demographics in $2011,{ }^{[10]}$ while the minority groups are overrepresented.

In an attempt to address past inequality, at least $60 \%$ of offers made by medical schools are to black and coloured students. Of the students who accept offers, at least $60 \%$ are black and coloured.

The percentage of female students is higher than that of male students. Only the UFS sets a gender ratio of 60:40 female/male in order to ensure that the minority male gender among the applicants is represented.

Various indices of disadvantage (such as quintile 1 and 2 schools, ${ }^{[7]}$ rural origin, disadvantaged population groups) have been suggested for inclusion, in order to address disadvantage effectively and to move beyond race as an indicator of disadvantage, especially when taking the emerging black middle class into account. However, more precise indicators of disadvantage may have to be developed for use in selection, or for deciding on students who may not fulfil the minimum academic requirements set in selection policies. Furthermore, culturally sensitive selection tools need to be explored in order to address issues related to cultural, socioeconomic and language diversity, which may affect students' possible selection. For example, students from lower socioeconomic backgrounds may not have access to the wide array of cultural and sporting activities or leadership development compared with those from privileged backgrounds, placing them at a further disadvantage when these items are included in non-academic selection criteria. The erratic quality of secondary school education in $\mathrm{SA}^{[9]}$ also leads to disadvantage, particularly for students whose schooling is affected by sociopolitical upheaval, poor teaching proficiency or lack of adequate learning resources. This is not limited to schools in rural areas or even historically black residential areas such as urban informal settlements.

In order to address socioeconomic disadvantage effectively, students from poor backgrounds must have greater access to bursaries and financial support for the duration of their studies. As stated by the $\mathrm{WHO}^{[12]}$ in 2013: 'It is clear that admission procedures by themselves will not overcome inequalities in healthcare systems. Where targeted admission policies are used, support mechanisms must be in place to ensure conditions in which students are able to complete programmes. ... Currently many students who do not complete their courses 
do so for financial reasons, so disadvantaged students would need financial support. ${ }^{\text {[12] }}$

\section{Conclusion}

The demographic profile of medical students selected at SA universities is moving closer to the population distribution of SA. However, the percentage of black students is still lower than that in the general population, while white, Indian/Asian and coloured students are overrepresented in relation to the general population.

Current policies target black and coloured students for selection into undergraduate medical programmes across all medical schools in SA. However, race-based selection policies may be inadequate for addressing historical inequalities. Indices of disadvantage such as origin in rural or underserved communities (possibly linked to poorer educational opportunities) and socioeconomic status should be considered to improve access. In compliance with international trends, both academic and non-academic indicators are used in the selection process. Stronger evidence is now needed to link throughput, academic success and possibly even future career paths to selection processes.

It is worth noting, however, that the quality and values of these graduates - irrespective of where they come from - are influenced by the training curriculum, quality of teaching and role models they are exposed to once they are enrolled in medical school.

Acknowledgements. We thank Dr Daleen Struwig, Faculty of Health Sciences, UFS, for technical and editorial preparation of the manuscript.

\section{References}

1. Bore M, Munro D, Powis D. A comprehensive model for the selection of medical students. Med Teach 2009;31(12):1066-1072. [http://dx.doi.org/10.3109/01421590903095510] [PMID 19995169]

2. Koenig TW, Parrish SK, Terregino CA, Williams JP, Dunleavy DM, Volsch JM. Core personal competencies important to entering students' success in medical school: What are they and how could they be assessed early in the admission process? Acad Med 2013;88(5):603-613. [http://dx.doi. org/10.1097/ACM.0b013e31828b3389]

3. Ross D, Loeffler K, Schipper S, Vandermeer B, Allan GM. Do scores on three commonly used measures of critical thinking correlate with academic success of health professions trainees? A systematic review and meta-analysis. Acad Med 2013;88(5):724-734. [http://dx.doi.org/10.1097/ systematic review and meta-analysis. Acad

4. Kuncel NR, Ones DS, Hezlett SA. A comprehensive meta-analysis of the predictive validity of the 4. Kuncel NR, Ones DS, Hezlett SA. A comprehensive meta-analysis of the predictive validity of the
graduate record examinations: Implications for graduate student selection and performance. Psychol Bull 2001;127(1):162-181. [http://dx.doi.org/10.1037/0033-2909.127.1.162]

5. Benbassat J, Baumal R. Uncertainties in the selection of applicants for medical school. Adv Health Sci Educ 2007;12(4):509-521. [http://dx.doi.org/10.1007//10459-007-9076-0

6. Lehmann U, Andrews G, Sanders D. Change and Innovation at South African Medical Schools - An Investigation of Student Demographics, Student Support and Curriculum Innovation. Durban: Health Systems Trust, 2000. http://indicators.hst.org.za/uploads/files/medschools.pdf (accessed 22 June 2015).

7. Western Cape Government, Department of Education. Background to the national quintile system. Media release 14 October 2014. http://wced.pgwc.gov.za/comms/press/2013/74_14oct.html (accessed 30 June 2015).

8. Naidoo SS, van Wyk J, Higgins-Opitz SB, Moodley K. An evaluation of stress in medical students at a South African university. S Afr Fam Pract 2014;565(5):258-262. [http://dx.doi.org/10.1080/207861 90.2014.980157]

9. Spaull N. South Africa's education crisis: The quality of education in South Africa 1994-2011. Report Commissioned by Centre for Development and Enterprise (CDE), October 2013. http://www. section27.org.za/wp-content/uploads/2013/10/Spaull-2013-CDE-report-South-Africas-Educationsection27.org.za/wp-content/upl
Crisis.pdf (accessed 30 June 2015)

10. Statistics South Africa. Census 2011. Statistical release (revised) P0301.4. www.statssa.gov.za/ publications/P03014/P030142011.pdf (accessed 28 July 2015)

11. Grobler L, Marais BJ, Mabunda SA, Marindi PN, Reuter H, Volmink J. Interventions for increasing the proportion of health professionals practising in rural and other underserved areas. Cochrane Database Syst Rev 2009, Issue 1. Art. No.: CD005314. [http://dx.doi.org/10.1002/14651858.CD005314.pub2]

12. World Health Organization. Transforming and scaling up health professionals' education and training. Geneva: WHO, 2013. http://apps.who.int/iris/bitstream/10665/93635/1/9789241506502_eng.pdf (accessed 30 June 2015)

13. Digby A. Black doctors and discrimination under South Africa’s apartheid regime. Med Hist 2013;57(2):269-290. [http://dx.doi.org/10.1017/mdh.2012.106]

Accepted 28 September 2015. 